\title{
Zinc-based metal oxoclusters: towards enhanced EUV absorptivity
}

\author{
Neha Thakur*a, Michaela Vockenhuber ${ }^{\mathrm{b}}$, Yasin Ekinci ${ }^{\mathrm{b}}$, Sonia Castellanos ${ }^{\mathrm{a}}$ \\ ${ }^{a}$ Advanced Research Center for Nanolithography, Science Park 106, Amsterdam 1098XG, The \\ Netherlands; 'Paul Scherrer Institute, Forschungstrasse 111, Villigen 5232, Switzerland.
}

\begin{abstract}
The cost-effectiveness and future progress of EUV $(13.5 \mathrm{~nm})$ lithography will largely depend on the resist technology development. Hybrid inorganic-organic photoresists have emerged as promising materials of EUV and have gained increasing attention in recent years. A crucial aspect for hybrid materials is their stability and the preservation of their molecular integrity when deposited as thin films. In this work, we study novel zinc ( $\mathrm{Zn}$ ) oxoclusters as molecular hybrid photoresists. Our aim is to combine the reactivity of methacrylate organic ligands with an inorganic cluster with high EUV photon absorption cross-section arising from this metal. To gain understanding on the shelf life of this material, changes in their structure under different conditions were monitored employing a combination of different spectroscopic techniques. The sensitivity of these oxoclusters under EUV light was investigated and their patterning performance is evaluated using EUV interference lithography. Our results indicate that these novel Zn-based oxoclusters are promising candidates for EUV lithography owing to their high dose sensitivity. Nevertheless, the labile nature of the methacrylate ligands has an important impact in the development process which seems to hamper their reproducibility. This work contributes to the understanding of the pitfalls and advantages of hybrid molecular resists.
\end{abstract}

Keywords: metal oxoclusters, EUV photoresist, stability, sensitivity

\section{INTRODUCTION}

Photoresists are the vital materials for the semiconductor industry since these materials mediate the transfer of information from an optically projected pattern to a substrate where the actual circuitry of processor chips and memory devices is built. ${ }^{1,2}$ To keep following Moore's law, which requires the transferring of ever higher resolution patterns, i.e. smaller critical dimensions, EUV lithography at $13.5 \mathrm{~nm}$ wavelength is seen as the most suitable successor to the stateof-the-art ArF photolithography (193 nm). The mentioned big jump in wavelength has however led to critical challenges for the development of suitable EUV photoresists. For adequate lithography performance, resists should simultaneously satisfy resolution $(<10 \mathrm{~nm}$ ), line-width roughness (LWR $<15 \%)$ and sensitivity (dose $<20 \mathrm{~mJ} / \mathrm{cm}^{2}$ ) at sustainable production costs..$^{3-6}$

Though the standard platform for resist materials have been polymer-based chemically amplified resists (CAR's), EUV lithography application demands an entirely new platform for resist development. ${ }^{3,7,8}$ As the future process nodes are continuously decreasing, the size of traditionally used polymers in photoresists cannot be ignored. In addition, the enhancement of absorption of EUV photons by the resist materials is one of the approaches to optimize their performance. This motivates for the research on new materials that incorporate elements with high EUV absorption cross-sections but are composed of small units in agreement with the targeted future resolutions. ${ }^{7,9-12}$

Metal oxoclusters are hybrid molecular compounds that are ideal platforms for this purpose. By choosing the right metalcomponent, they can meet the desired properties for EUV photon absorption and they are intrinsically small and have a homogeneous size (monodispersity). ${ }^{4,13}$ In the present contribution, the elucidation of a simple and versatile preparation method of a new Zn-based metal oxocluster, as well as the stability and EUV photochemistry of the resulting material are explored. Recently, molecular materials based on Zn have been investigated and have shown promising results. ${ }^{11,14,15}$ In our approach, a denser Zn metallic oxo core is used as the building block in order to enhance the EUV absorbance of the material. The organic ligands surrounding a condensed EUV absorbing core are envisioned as the main factor for the solubility properties and play a major role in the reactivity of the material, which determines in turn the solubility switch upon exposure. In this study, we focus on trifluoroacetate (TFA) and methacrylate (MA) ligands constituting the organic shell around a tetrameric $\mathrm{Zn}$ oxo core. The presence of fluorine element in a resist material is known to increase the EUV photon absorption. On the other hand, the introduction of MA ligands having a terminal double bond is anticipated to provide an effective solubility switch arising from the cross-linking of these double bonds. ${ }^{4,16}$ 
The study of the EUV lithographic performance on Zn-based oxoclusters featuring both types of ligands, as well as their shelf life, will be used to shed light on importance of the selection of proper ligands for an optimal design of hybrid EUV resists. New developers that can have specific interactions with this type of hybrid materials are also explored to improve the contrast of the material. These investigations highlight the importance of understanding the chemistry of the resist at the molecular level, and thereby optimize their performance.

\section{MATERIALS AND METHODS}

\subsection{Materials}

All chemicals were purchased from Sigma-Aldrich and used without purification. All the solvents were reagent grade.

\subsection{Synthesis of photoresist}

Methacrylic acid (MAA, $12.0 \mathrm{eq}$ ) and $\mathrm{Zn}_{4} \mathrm{O}(\mathrm{TFA})_{6}(1.0 \mathrm{eq})$ were dissolved in chloroform and left stirring for 2.5 hours at $40{ }^{\circ} \mathrm{C}$. The solvent is then evaporated and the oily residue is precipitated by washing with toluene. The process was repeated for 5-6 times to remove excess MAA in the reaction mixture and obtain a solid white compound. Crystallization at $4{ }^{\circ} \mathrm{C}$ in toluene overnight yielded the crystalline product, which was isolated by centrifugation/filtration and dried at $40{ }^{\circ} \mathrm{C}$ inside a vacuum oven. (Figure 1)

NMR (300 MHz): ${ }^{1} \mathrm{H}$ NMR $\delta: 1.83\left(3 \mathrm{H}, \mathrm{CH}_{3}\right), 5.34,\left(1 \mathrm{H},=\mathrm{CH}_{2}\right), 5.83\left(1 \mathrm{H},=\mathrm{CH}_{2}\right) \mathrm{ppm}$

${ }^{19} \mathrm{~F}$ NMR (300 MHz) $\delta:-73.94\left(\mathrm{CF}_{3}\right) \mathrm{ppm}$

FTIR: $523\left(\mathrm{w}, v_{\text {as }} \mathrm{Zn}-\mathrm{O}-\mathrm{Zn}\right), 1205-1155(\mathrm{~m}, v \mathrm{C}-\mathrm{F}), 1238\left(\mathrm{~m}\right.$, coupled rocking $=\mathrm{CH}_{\mathrm{x}}$ and $\left.\mathrm{v} \mathrm{C}-\mathrm{C}\right), 1400-1500(\mathrm{~s}$, coupled $\mathrm{CH}_{\mathrm{X}}$ deformations and $v_{\mathrm{s}} \mathrm{COO}$ ), 1543 (s, $v_{\text {as }} \mathrm{COO}$, bonded acid MA), 1606 (m, COO H-bonded MA), 1653 (s, $v_{\text {as }} \mathrm{C}=\mathrm{C}$ ), 1687 (s, vas $\mathrm{COO}$ bonded TFA), 1735 (w, vas $\mathrm{COOH}$ non-bonded TFA), 2960 (w, v = $\mathrm{CH}_{2}$ ), 3200-3600 (b, $\left.v_{\mathrm{s}} \mathrm{O}-\mathrm{H}\right) \mathrm{cm}^{-1}$

\subsection{Characterization of the bulk material}

NMR was recorded using a Bruker AV-400 NMR spectrometer using DMSO as a solvent. FT-IR was performed in a Bruker ALPHA FTIR spectrometer. Mass spectra were collected on an AccuTOF LC, JMS-T100LP Mass spectrometer (JEOL). The thermogravimetric analysis (TGA) was performed using NETZSCH thermogravimetric analyser in an $\mathrm{Al}_{2} \mathrm{O}_{3}$ crucible and heating was performed from $35^{\circ} \mathrm{C}$ to $700^{\circ} \mathrm{C}$ at $10 \mathrm{~K} / \mathrm{min}$ in an $\mathrm{N}_{2} / \mathrm{O}_{2}$ atmosphere. Elemental analysis was performed by Mikroanalytisches Labor Kolbe, Germany for elements Zn, Carbon (C) and Flourine (F) in the synthesized compound $\mathrm{Zn}(\mathrm{MA})(\mathrm{TFA})$.

\subsection{Thin films preparation}

$\mathrm{Zn}$ (MA)(TFA) resist solution $2 \%(\mathrm{w} / \mathrm{v})$ was prepared in chloroform $\left(\mathrm{CHCl}_{3}\right)$, and propylene glycol methyl ether acetate, PGMEA $(9: 1 \mathrm{v} / \mathrm{v})$ followed by filtration using $0.22 \mu \mathrm{m}$ PTFE filter. Thin films were prepared by spin coating the resist solution at $2100 \mathrm{rpm}, 3000 \mathrm{rpm} / \mathrm{s}$ for $30 \mathrm{~s}$. Post application baking was applied for $30 \mathrm{~s}$ at $90^{\circ} \mathrm{C}$ to remove excess of the residual solvent.

Samples for UV-vis absorption spectroscopy were spin coated on quartz substrates of $525 \mu \mathrm{m}$ thickness and samples for FTIR spectroscopy were spin coated on a double side polished Si-wafer of $200 \mu \mathrm{m}$ thickness.

\subsection{Characterization of thin films}

UV-vis absorption spectroscopy was performed in a Shimandu UV2600 spectrophotometer and FTIR spectroscopy of the thin films was performed in transmission mode under vacuum in a Bruker Vertex 80v spectrometer.

\subsection{EUV exposure and Post-exposure analysis}

Open frame exposures were performed for a wide range of doses by exposing $1.7 \times 1.7 \mathrm{~mm}^{2}$ areas to EUV light at 13.5 $\mathrm{nm}$. These exposures were performed at the SLS XIL-II beamline in Paul Scherrer Institute (PSI), Switzerland. Diluted propionic acid, acetylacetone (acac) and acetic acid in $\mathrm{CHCl}_{3}$ were tested as developers. The thin film thickness was measured by Atomic Force microscopy (AFM), using a Bruker Dimensions Icon. High resolved SEM images were recorded using FEI Verios 460 system. 


\section{RESULTS AND DISCUSSIONS}

\subsection{Determination of the organic shell composition}

The $\mathrm{Zn}$ oxocluster (Zn(MA)(TFA)) was synthesized by ligand exchange method from the commercially available Oxo[hexa(trifluoroacetato)]tetrazinc $\mathrm{Zn}_{4} \mathrm{O}$ (TFA) 6 . The starting material comprises a core of four $\mathrm{Zn}$ atoms bridged by one $\mathrm{O}$ atom $\left(\mu_{4}-\mathrm{O}\right)$ and six trifluoroacetate ligands that bridge two $\mathrm{Zn}$ atoms through the carboxylate group. ${ }^{17,18}$ Since this reaction proceeds in equilibrium due to competitive binding of the two types of carboxylate ligands, methacrylate acid is added in excess to favour the shift of the equilibrium to the right side of the chemical equation and have a high abundance of methacrylate ligand in the shell.

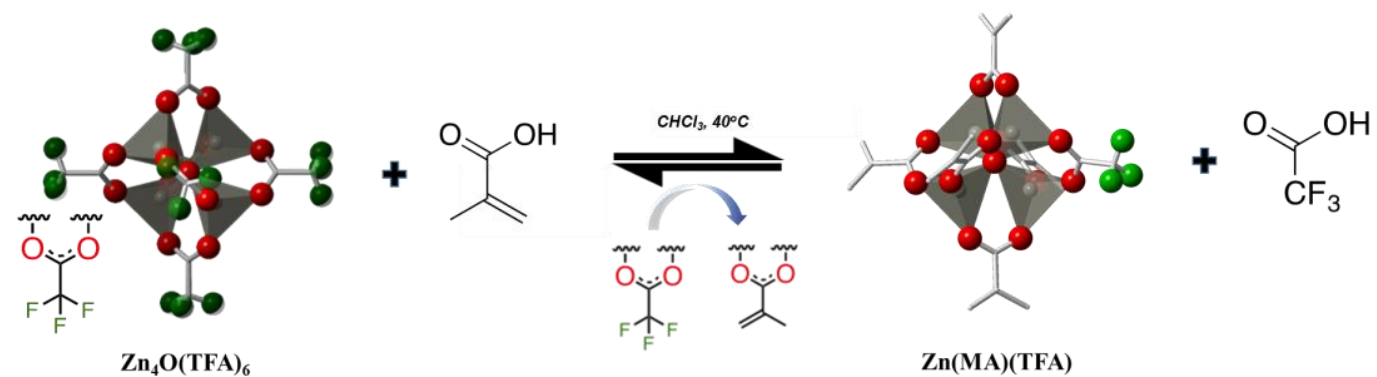

Figure 1. Representation of scheme for the synthesis of $\mathrm{Zn}(\mathrm{MA})(\mathrm{TFA})$ by ligand exchange from commercial available $\mathrm{Zn} 4 \mathrm{O}(\mathrm{TFA}) 6$.

NMR and FTIR spectroscopic analysis performed on the synthesized bulk oxocluster confirmed the presence of both TFA and MA. To confirm that the tetrameric oxocluster is preserved during ligand exchange, mass spectrometry experiments were performed. This is an ideal technique for this purpose since $\mathrm{Zn}$ metal has different naturally occurring isotopes, which provides the mass spectrum with a unique characteristic isotopic pattern distribution arising from the four $\mathrm{Zn}$ atoms in the oxocluster. The spectra obtained using a different solvents for the vaporization step are shown in Figure 2 and Figure 3.

The observed isotopic distribution observed in mass spectra was in concordance to the expected isotopic distribution. The molecular peak was confirmed by the detection of $\left[\mathrm{Zn}(\mathrm{MA})_{5}+2 \mathrm{CH}_{3} \mathrm{CN}\right]^{+}$and $\left[\mathrm{Zn}(\mathrm{MA})_{4}(\mathrm{TFA})+2 \mathrm{CH}_{3} \mathrm{CN}\right]^{+}$. (Figure 2) The complexation of acetonitrile to the cluster was confirmed by recording mass in deuterated acetonitrile- $\mathrm{d}_{3}$, which shifted the envelope of peaks with the specific isotopic distribution by $+6 \mathrm{~m} / \mathrm{z}$ unit. Furthermore, when the spectrum was recorded using methanol as the carrying solvent, the molecular peak was observed at $702 \mathrm{~m} / \mathrm{z}$, corresponding to $\left[\mathrm{Zn}(\mathrm{MA})_{5}\right]^{+}$(Figure 3 ).

The composition of the organic shell (TFA/MA ratio) was determined by using elemental analysis. The results (\% Zn: 23.86, \% C: $37.24, \% \mathrm{~F}: 7.29)$ matched the chemical formula $\left[\mathrm{Zn}_{4} \mathrm{O}_{18} \mathrm{C}_{31} \mathrm{H}_{37.5} \mathrm{~F}_{4.5}\right]$, corresponding to the tetrameric cluster core having on an average of $7 \mathrm{MA}$ and 1.5 TFA. This evidences the presence of an excess on non-bonded carboxylic acid in the bulk material, in agreement with IR and TGA. The occlusion of carboxylic acids that are occluded in the crystals of the metal oxoclusters is a common phenomenon. ${ }^{17,19,20}$

The residue detected experimentally in TGA was $32 \%$ (Figure 4), in good agreement to the calculated $\mathrm{ZnO}$ residue that results from the combustion of compound with molecular formula $\mathrm{Zn}_{4} \mathrm{O}_{18} \mathrm{C}_{31} \mathrm{H}_{37.5} \mathrm{~F}_{4.5}$ (32\%). The initial loss of about 5\% as a first step at $125^{\circ} \mathrm{C}$ could correspond to the evaporation of the non-bonded TFA from the bulk material, whereas the excess of MAA might be lost in a gradual manner. 


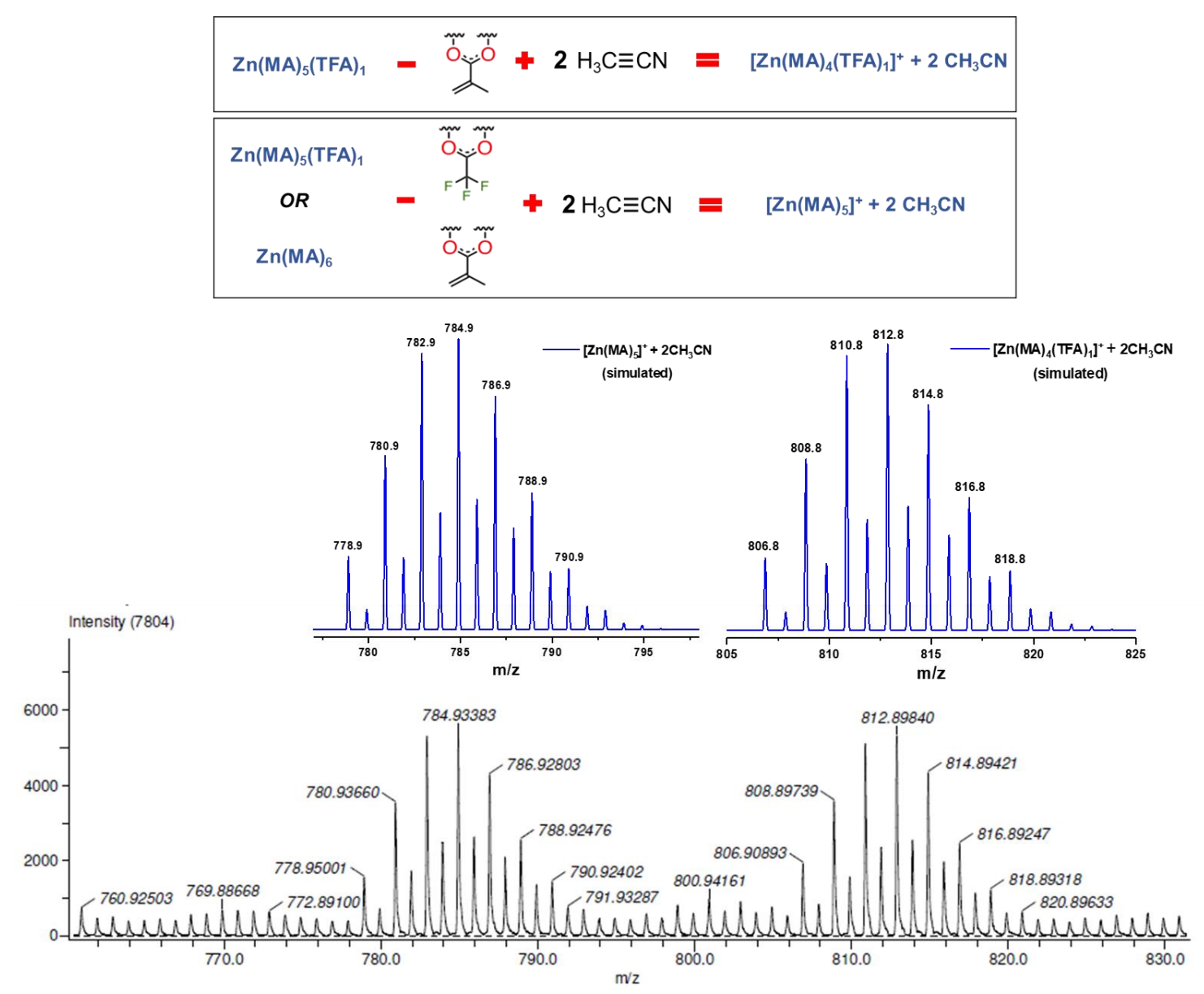

Figure 2. Mass spectra for synthesized $\mathrm{Zn}(\mathrm{MA})(\mathrm{TFA})$ oxocluster experimental and simulated (blue)

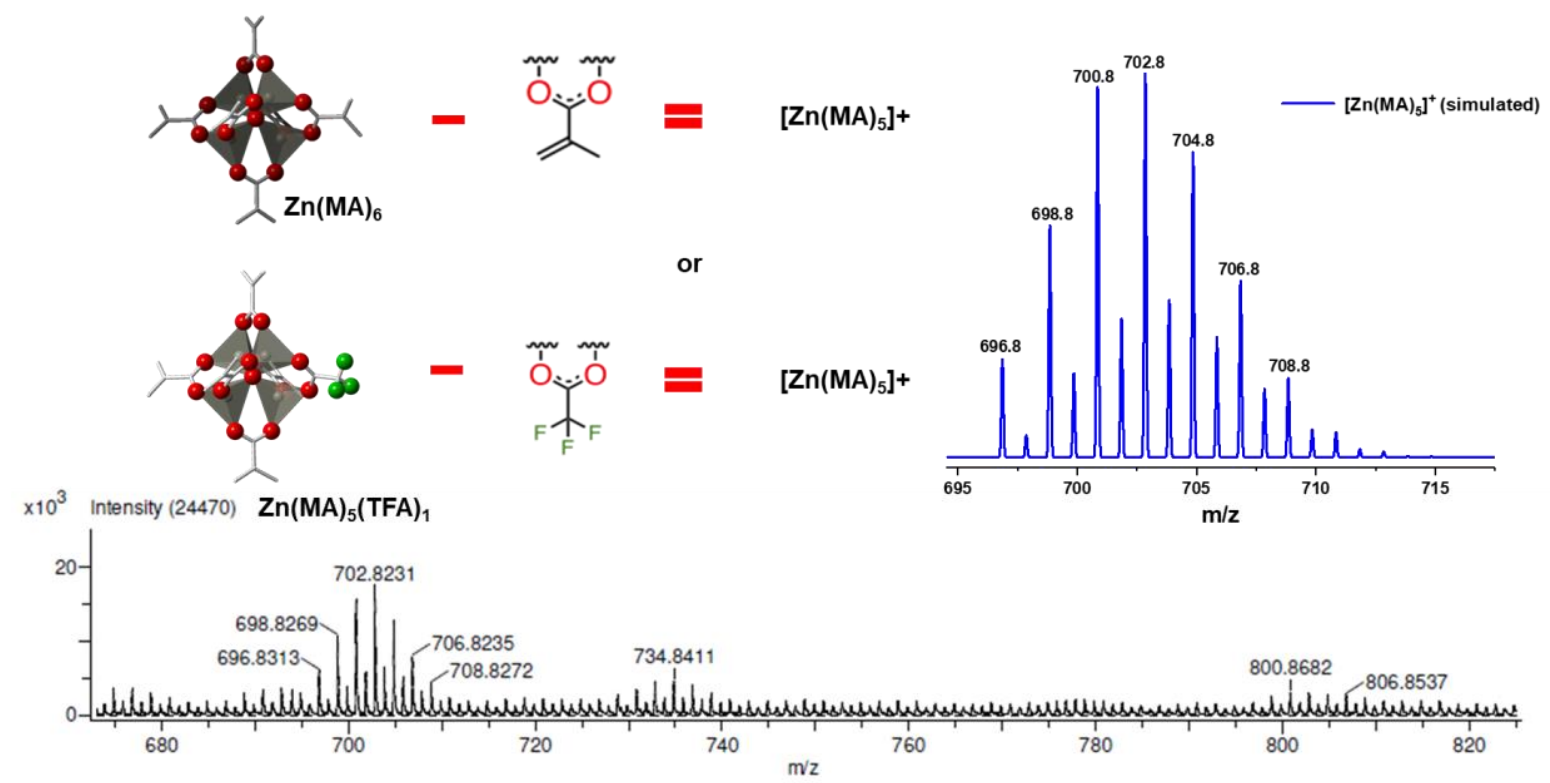

Figure 3. ESI mass spectra of $\mathrm{Zn}(\mathrm{MA})(\mathrm{TFA})$ recorded in methanol as solvent. 


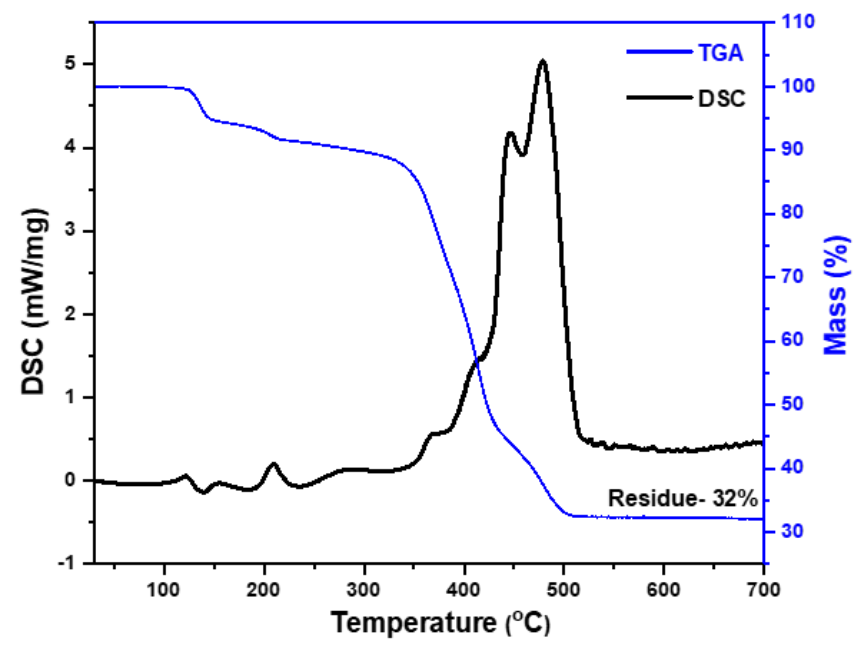

Figure 4. TGA-DSC for the powdered sample of Zn(MA)(TFA).

\subsection{Stability studies}

Given that the carboxylate ligands bonded to $\mathrm{Zn}$ core are rather labile, it was crucial to study the stability of the bulk material and thin films. This included studies of bulk material stored in moisture-free conditions and thin films under different atmospheres.

The stability of bulk material was studied by FTIR spectroscopy. For the synthesized compound a significant increase in the intensity of O-H band was observed in the normalized IR spectra's which could result from hydrolysis and a decrease in the $v_{\text {as }}$ of non-bonded TFA $\left(1725 \mathrm{~cm}^{-1}\right)$ signifies the loss of free acid over a period of 2 months. Yet, the presence of the characteristic Zn-O-Zn stretching band of the tetrameric oxo core ${ }^{21}$ indicates that the degradation was only partial. The broadening of the COO stretching bands at $1605 \mathrm{~cm}^{-1}$ also suggests change in the environment of carboxylates over the aforementioned period of time. (Figure 5)

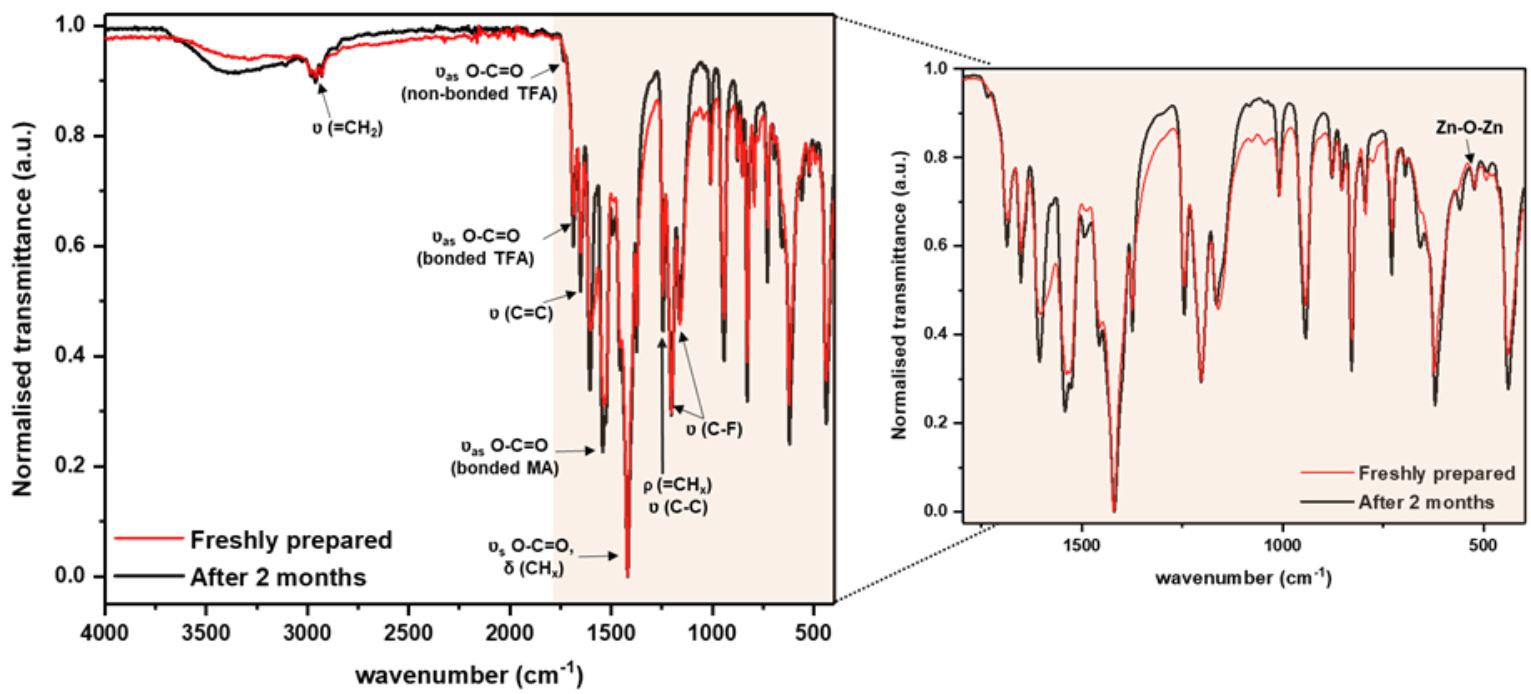

Figure 5. Normalised FTIR spectra recorded for freshly synthesized oxocluster Zn(MA)(TFA) and after 2 months. 
In addition to the stability of the bulk material, it was crucial to investigate the molecular structure of the oxoclusters when deposited as a thin film and the effect of different atmospheres present in the lithographic process. The stability of the thin film was monitored at room conditions, nitrogen atmosphere (glovebox), and high vacuum. The latter is highly relevant since EUV exposure is performed under high vacuum, which may act as a driving force for ligands loss and undesired aggregation of the inorganic clusters. ${ }^{16,22}$ The evolution of the thin films after different treatments was analysed by UV-vis absorption and FTIR spectroscopy.

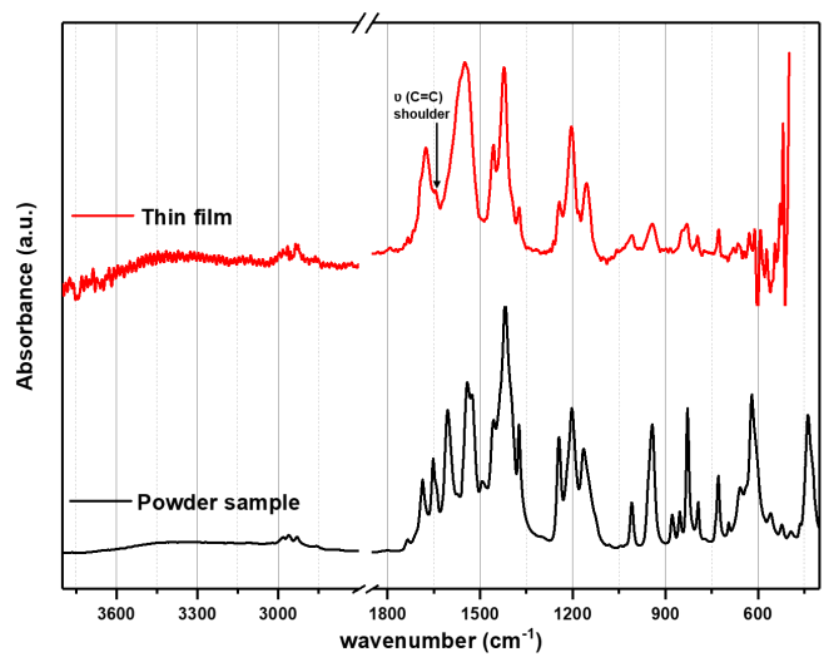

Figure 6. Normalised FT-IR absorption spectra of bulk Zn(MA)(TFA) and its thin film.

We investigated, first, the composition of the thin film right after deposition by spin-coating. FTIR absorption spectra recorded for Zn(MA)(TFA) thin film show that the extra carboxylic acids initially present in the bulk crystalline material seem to be lost during spin-coating since the bands at $1725 \mathrm{~cm}^{-1}$ (assigned to the $\mathrm{COOH}$ asymmetric stretching of the non-bonded trifluoroacetic acid) and at $1606 \mathrm{~cm}^{-1}$ (tentatively assigned $\mathrm{COOH}$ of methacrylate acid bonded to the $\mathrm{Zn}$ cluster in a weak manner ${ }^{23}$ ) were not observed in the thin film FTIR spectrum. The presence of bonded methacrylate ligand was evidenced by the peak at $1543 \mathrm{~cm}^{-1}$ (COO bidentate asymmetric stretching), the envelope at $1500-1300 \mathrm{~cm}^{-1}$ (various chelating and bridging $\mathrm{COO}$ stretching modes), and the vibrational modes corresponding to $v_{\mathrm{s}} \mathrm{C}=\mathrm{C}$ at $1653 \mathrm{~cm}^{-1}$ (observed as a shoulder) and the peak at $1238 \mathrm{~cm}^{-1}$ corresponding to coupled rocking $=\mathrm{CH}_{\mathrm{x}}$ and $v \mathrm{C}$-C. The presence of coordinated TFA was indicated by the intense peak $1675 \mathrm{~cm}^{-1}$ (COO asymmetric stretching of bonded TFA, which splits or shifts compared to the powder sample, $1687 \mathrm{~cm}^{-1}$ ) and the characteristic C-F stretchings at 1155 and $1205 \mathrm{~cm}^{-1}$.

The presence of the MA in the Zn(MA)(TFA) oxocluster allows to monitor the stability of the thin film by UV-vis spectroscopy, since it confers the material an absorption band at $\sim 210 \mathrm{~nm}$ due to $\pi \rightarrow \pi^{*}$ electronic transition involving the terminal double bond. The UV-vis spectrum of the freshly spin coated thin film was compared to the spectra for same thin film after certain intervals in air atmosphere, as shown in Figure 7a. The spin coated thin film was stable at least for 4.5 hours and bleaching was clearly observed after 24 hours. Similarly, the stability was monitored after applying high vacuum $\left(\sim 2 * 10^{-6} \mathrm{mbar}\right)$ for 1 hour resulting in a slight decrease in the absorption band suggesting that vacuum did not induce a considerable loss of ligands. Another measurement was performed after leaving the latter sample for 3.5 hours at room temperature, which signifies negligible change in the absorption band during this period of time (Figure 7b).

In order to further investigate specific changes in the organic ligands, FTIR of the thin films was recorded. The spectra were recorded for the freshly prepared sample and for samples after 24 hours in different atmospheres. By comparing the normalised absorption spectra (Figure 7c), a concomitant slight decrease in the intensities of the peaks at $1421 \mathrm{~cm}^{-1}$ (for $\mathrm{CH}_{\mathrm{X}}$ deformations combined with $\mathrm{COO}$ symmetric stretching's) and of the small shoulder at $1238 \mathrm{~cm}^{-1}$ (due to rocking of vinylic methylene group $=\mathrm{CH}_{2}$ and $\mathrm{C}-\mathrm{C}$ stretching of neighbouring groups $)^{22}$ is observed for the sample kept in $\mathrm{N}_{2}$ which could result from structural reorganizations. Yet, a more dramatic decrease of these bands and broadening of the peaks at 1675 and $1543 \mathrm{~cm}^{-1}$ was detected for the sample kept at room conditions, accompanied by a relative increase in the broad band at $3100-3600 \mathrm{~cm}^{-1}$, typical for O-H stretching. 
(a)

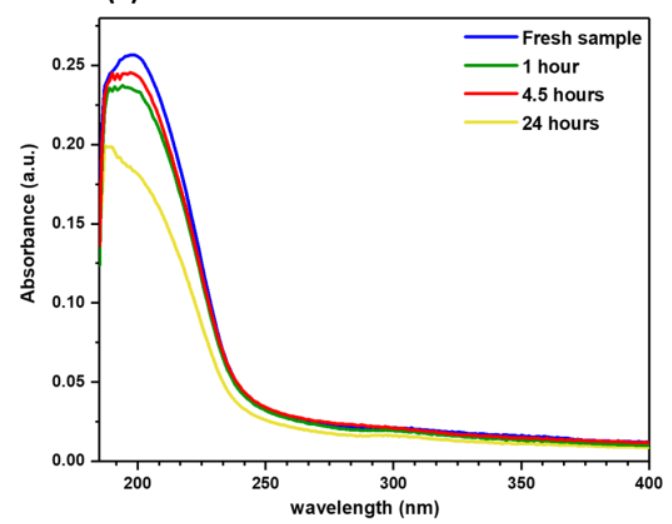

(c)

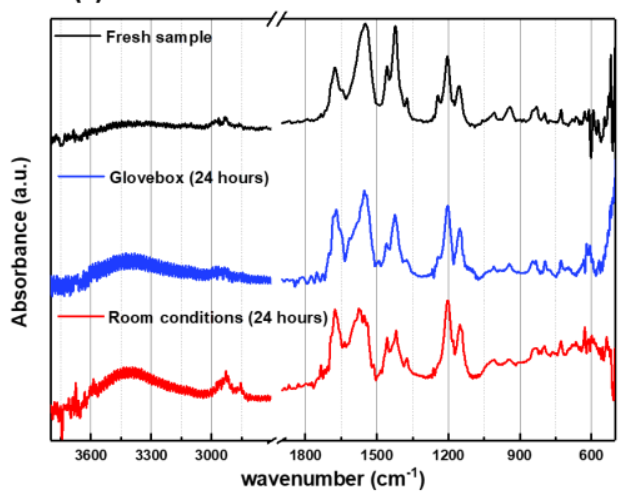

(b)

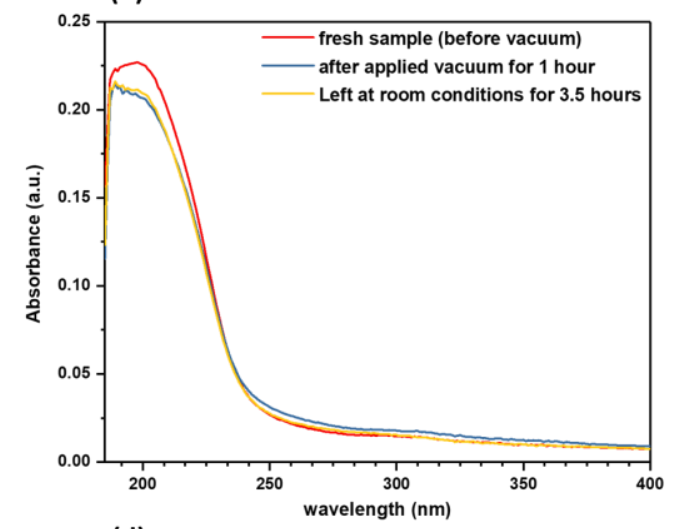

(d)

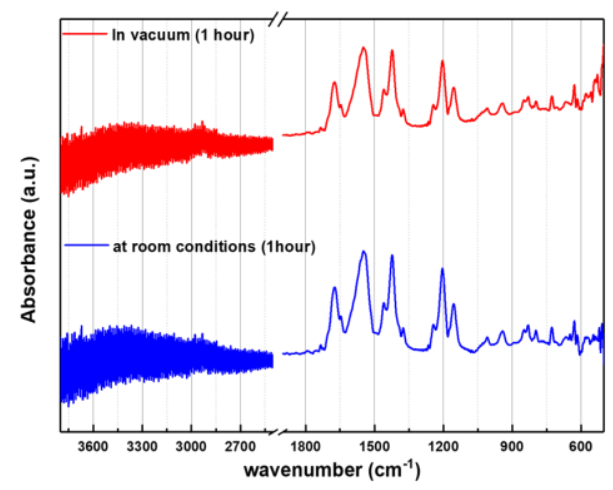

Figure 7. Monitoring stability of thin film of Zn(MA)(TFA) photoresist by UV-vis absorption spectra (a, b) and FT-IR absorption spectra $(\mathrm{c}, \mathrm{d})$.

These experiments suggest that moisture in the air (or trapped in the thin film, in the case of the sample stored in $\mathrm{N}_{2}$ ) can lead to a partial hydrolysis of $\mathrm{Zn}(\mathrm{MA})$ (TFA) cluster. Also, polymerization of the terminal double bond could also be favoured by the natural light available at room conditions. The bands in FTIR spectra of the sample before and after high vacuum showed no appreciable change suggesting that vacuum did not induce a significant loss of organic ligands. (Figure 7d). Subsequent monitoring of the same sample after one hour at room conditions was in agreement with the UV-vis spectroscopy studies and evidenced that no significant hydrolysis occurred within this time frame.

\subsection{Sensitivity towards EUV light and lithographic performance}

The interaction of the developer with the unexposed and exposed resist largely define the contrast in the lithographic process. Therefore, choosing the right developer is crucial to obtain a good contrast and understanding the molecular structure in thin films can greatly assist in the choice. Our first attempt was to use chloroform as developer, which can easily dissolve the bulk powder. However, it could not re-dissolve the compound once thin film was spin coated on the substrate. This is another evidence that upon thin film formation, the changes in material from original bulk (loss of excess of non-bonded acids as seen in FTIR and potentially a certain extent of structural rearrangements) affects the solubility.

Thus, contrast curves were obtained for $\mathrm{Zn}(\mathrm{MA})(\mathrm{TFA})$ photoresist by using different developers that could interact more strongly with the $\mathrm{Zn}$-clusters than pure chloroform and that could supplement the loss of the non-bonded acids during the thin film deposition or even compete with the existing carboxylate ligands. Diluted solutions $(0.05 \%)$ of propionic acid, acetylacetate (acac), and acetic acid in chloroform were tested. Different profiles in the contrast curve were obtained for each developer (Figure 8). While the resist behaved as a negative tone resist in all cases, we attribute this differences to distinct interactions with cluster, since these developers have different binding angles and charge distribution. Acetic acid, seemed to interact more strongly with the material than propionic acid, since it dissolved unexposed photoresist and partially the exposed area, as well. Acac, which is a strong chelating agent, did not yield a good contrast, and gave signs 
of also strong interaction with the exposed part. Among the tested developers, diluted propionic acid was thus considered a better developer rendering better contrast and hence was used for further lithography experiments. According to the low doses to gel observed for the three curves, Zn(MA)(TFA) displays high sensitivity towards EUV photons.

(a)

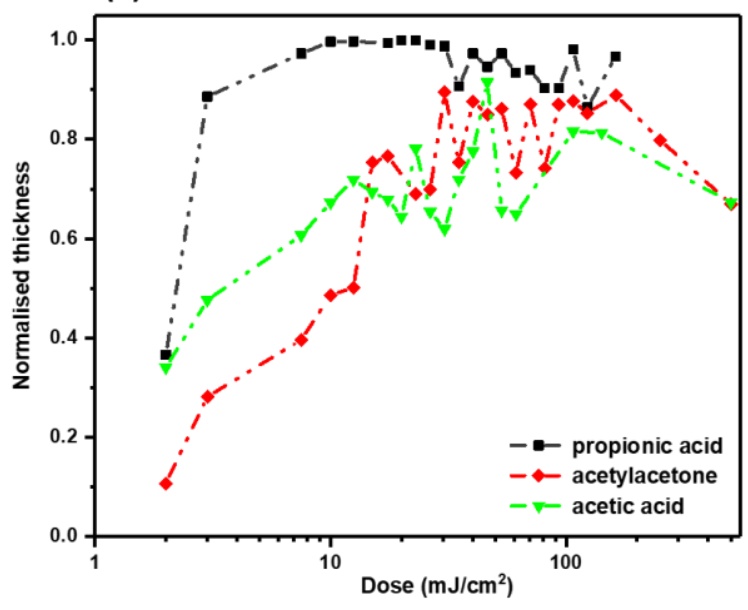

(b)

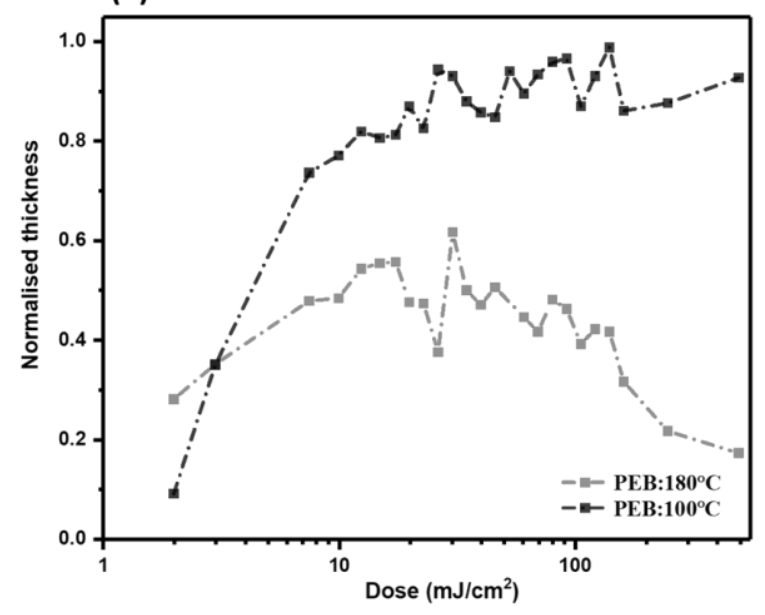

Figure 8. Contrast curves of EUV exposed $\mathrm{Zn}(\mathrm{MA})(\mathrm{TFA})$ : (a) developed with a diluted solution of different organic chelating agents; (b) response of photoresist at PEB $100^{\circ} \mathrm{C}$ and $180^{\circ} \mathrm{C}$.

The effect of post-exposure bake (PEB) at $100{ }^{\circ} \mathrm{C}$ and $180{ }^{\circ} \mathrm{C}$ applied for $30 \mathrm{~s}$ was also studied. According to the TGA of the powder samples, at these two temperatures the only expected processes are the desorption of non-bonded TFA and MAA. Yet, IR spectra indicate that these non-bonded acids are not present in the thin film, since they are lost during deposition. However, the contrast decreased upon application of PEB at $100{ }^{\circ} \mathrm{C}$ and was practically lost when PEB at $180{ }^{\circ} \mathrm{C}$ was employed. Further spectroscopic analysis to identify the structural changes induced at this temperature need to be performed in order to identify the process induced by the heating.

The lithography performance of $\mathrm{Zn}(\mathrm{MA})(\mathrm{TFA})$ was preliminary tested by patterning L/S features using EUV interference lithography (EUVL-IL). In figure 9, two selected patterns obtained for $30 \mathrm{~nm}$ half-pitch (HP) with two different batches of the material are shown. We observed that the material shows a good performance, yet the dose to size is not reproduced with accuracy, even when the two materials showed almost identical spectroscopic features (evidencing same composition) (Figure 10b). The contrast curves of the two batches also showed certain differences (Figure 10a). We suspect that the labile character of the carboxylate ligands might be the source of the change in the dose-to gel and contrast. On the one hand, they can lead to final different molecular structure with variations in the MA/TFA of the thin film. On the other hand, every new batch might have slightly different average of ligand mixture, even when following the same synthetic procedure. This can lead to a problem in the reproducibility of the lithography performance. 

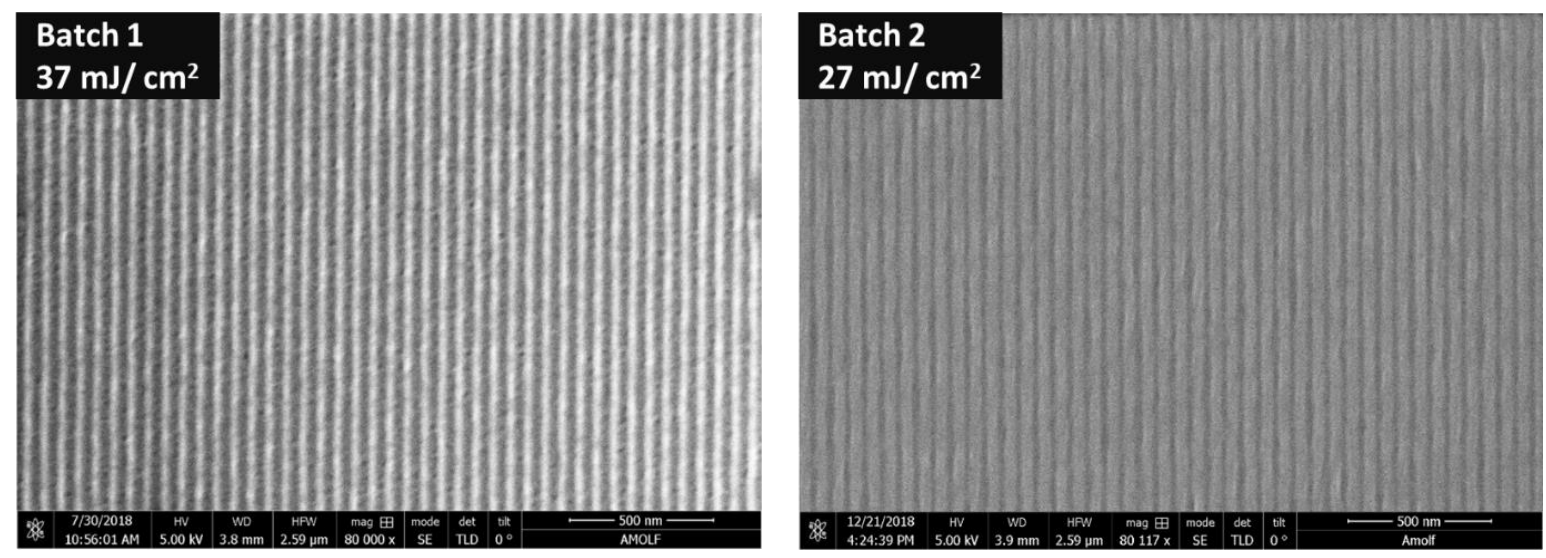

Figure 9. Fabricated L/S patterns for $30 \mathrm{~nm}$ HP for different batches of synthesized resist.

(a)

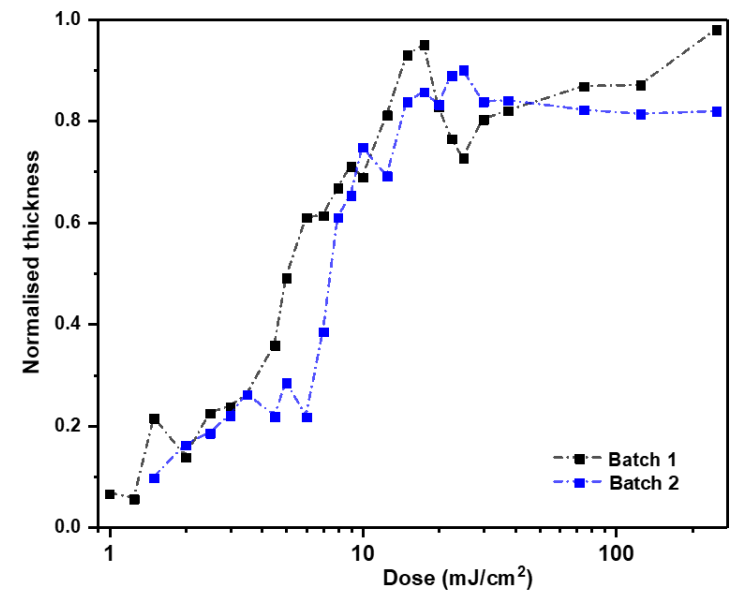

(b)

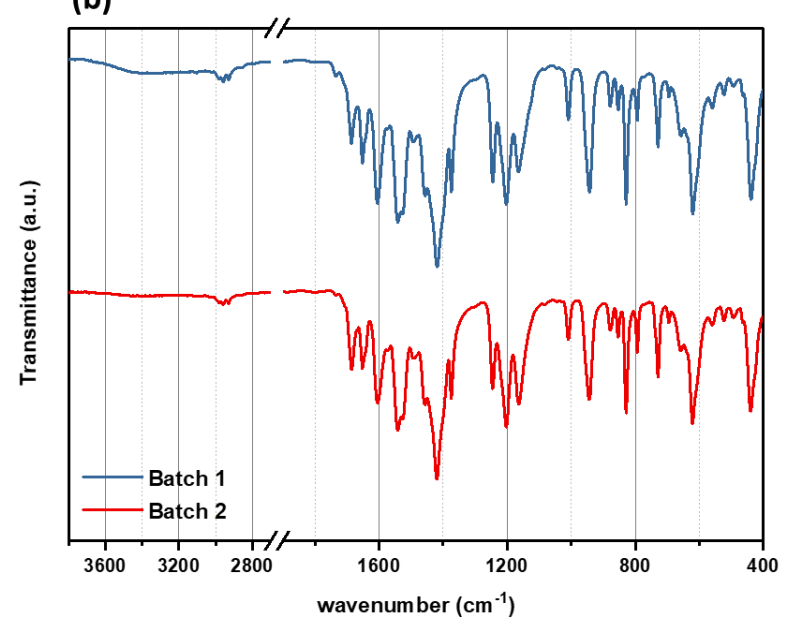

Figure 10. a) Contrast curves of EUV exposed Zn(MA)(TFA) synthesized in two different batches. b) IR spectra of the two batches (bulk powder)

\section{CONCLUSIONS}

The novel Zn-based oxoclusters featuring methacrylate and trifluoroacteate ligands possess small size, good film forming capability and high sensitivity towards EUV photons. Yet, deposition of the material as thin films changes its bulk solubility due to the loss of extra non-bonded acids that are occluded in the original crystalline forms and/or rearrangements of the carboxylate ligands. Our study on the stability of these clusters using spectroscopic techniques indicates that these oxoclusters having labile ligands are susceptible to undergo structural changes in two months' scale whereas thin films at room conditions seem to undergo polymerization or hydrolysis in a timescale of hours. Yet, the thin films are stable in air as well as in vacuum long enough (up to $4.5 \mathrm{~h}$ ) to perform the intact lithography application and processing. These results add information on the stability of such resist systems, which has an important aspect for the development of a new platform for hybrid photoresists. These hybrid inorganic-organic photoresists have displayed appreciable high sensitivity towards EUV light. Yet, the same liability which provides us with the synthetic versatility of ligand exchange reaction to tune the composition of the organic shell might also make them susceptible to undergo structural changes that might be a hindrance for the reproducibility of the lithographic performance. Further structural modifications, patterning mechanism study, dissolution studies, and lithography patterning optimization tests are ongoing. 


\section{ACKNOWLEDGEMENTS}

We thank Marco Wemekemp for his contribution in the resist synthesis experiments. We acknowledge the Paul Scherrer Institut, Villigen, Switzerland for the provision of beamtime at beamline XIL-II of the SLS (20180993). The research leading to these results has received funding from the European Community's Seventh Framework Programme (FP7/2007-2013) under grant agreement no. 312284 (CALIPSO, 20180993).

\section{REFERENCES}

[1] Chris Mack. "Fundamental Principles of Optical Lithography: The Science of Microfabrication," (John Wiley \& Sons, 2008).

[2] H. Xu, V. Kosma, E. P. Giannelis \& C. K. Ober. "In pursuit of moore's law: Polymer chemistry in action," Polymer Journal 50, 45-55 (2018).

[3] H. Xu, V. Kosma, K. Sakai, E. P. Giannelis \& C. K. Ober. "EUV photolithography: resist progress in metalorganic complex photoresists," J. Micro/Nanolithography, MEMS, MOEMS 18, 1 (2018).

[4] S. Castellanos, L. Wu, M. Baljozovic, G. Portale, D. Kazazis, M. Vockenhuber, Y. Ekinci \& T. Jung. "Ti, Zr, and Hf-based molecular hybrid materials as EUV photoresists," Proc. SPIE 10583, 105830A (2018).

[5] D. De Simone, P. Vanelderen \& G. Vandenberghe. "Photo Material Readiness at the Eve of EUVL HVM," $J$. Photopolym. Sci. Technol. 30, 613-617 (2017).

[6] D. De Simone, V. Rutigliani, G. Lorusso, P. De Bisschop, Y. Vesters, V. M. Blanco Carballo \& G. Vandenberghe. "EUV photoresist patterning characterization for imec N7/N5 technology," Proc. SPIE 10583, 105830G (2018).

[7] L. Li, X. Liu, S. Pal, S. Wang, C. K. Ober \& E. P. Giannelis. "Extreme ultraviolet resist materials for sub-7 nm patterning," Chem. Soc. Rev. 46, 4855-4866 (2017).

[8] R. Maas, M.-C. van Lare, G. Rispens \& S. F. Wuister. "Stochastics in extreme ultraviolet lithography: investigating the role of microscopic resist properties for metal-oxide-based resists," J. Micro/Nanolithography, MEMS, MOEMS 17, 1 (2018).

[9] J. E. Bjorkholm. "EUV lithography—-the successor to optical lithography," Intel Technol. J. 3, 98 (1998).

[10] M. Krysak, M. Leeson, E. Han, J. Blackwell \& S. Harlson. "Extending resolution limits of EUV resist materials," Proc. SPIE 9422, 942205 (2015).

[11] K. Kasahara, V. Kosma, K. Sakai, E. Giannelis, C. K. Ober, K. Yang \& H. Xu. "EUV metal oxide hybrid photoresists: ultra-small structures for high-resolution patterning," Extrem. Ultrav. Lithogr. IX 10583, 105831P (2018).

[12] P. D. Ashby, D. L. Olynick, D. F. Ogletree \& P. P. Naulleau. "Resist Materials for Extreme Ultraviolet Lithography: Toward Low-Cost Single-Digit-Nanometer Patterning," Adv. Mater. 27, 5813-5819 (2015).

[13] C. Ober, J. Jiang, B. Zhang, L. Li, E. Giannelis, J. S. Chun, M. Neisser \& R. Sierra-Alvares. "New developments in ligand-stabilized metal oxide nanoparticle photoresists for EUV lithography," Proc. SPIE 9422, 942207 (2015).

[14] H. Xu, K. Sakai, K. Kasahara, V. Kosma, K. Yang, H. C. Herbol, J. Odent, P. Clancy, E. P. Giannelis \& C. K. Ober. "MOF-inspired metal-containing clusters for high resolution patterning," Chem. Mater. 30, 4124-4133 (2018).

[15] V. Kosma, K. Kasahara, H. Xu, K. Sakai, C. K. Ober \& E. P. Giannelis. "Patterning mechanism of metal based hybrid EUV resists," Proc. SPIE 10583, 105831 U (2018).

[16] E. C. Mattson, Y. Cabrera, S. M. Rupich, Y. Wang, K. A. Oyekan, T. J. Mustard, M. D. Halls, H. A. Bechtel, M. C. Martin \& Y. J. Chabal. "Chemical Modification Mechanisms in Hybrid Hafnium Oxo-methacrylate Nanocluster Photoresists for Extreme§ Ultraviolet Patterning," Chem. Mater. 30, 6192-6206 (2018). 
[17] Y. Hayashi, T. Ohshima, Y. Fujii, Y. Matsushima \& K. Mashima. "A trifluoroacetic acid adduct of a trifluoroacetate-bridged $\mu 4$-oxo-tetranuclear zinc cluster, $\mathrm{Zn} 4(\mathrm{OCOCF} 3) 6 \mathrm{O} \cdot \mathrm{CF} 3 \mathrm{CO} 2 \mathrm{H}$ : Synthesis under mild conditions and catalytic transesterification and oxazoline formation," Catal. Sci. Technol. 1, 230-233 (2011).

[18] T. Ohshima. "Development of Tetranuclear Zinc Cluster-Catalyzed Environmentally Friendly Reactions and Mechanistic Studies," Chem. Pharm. Bull. 64, 523-539 (2016).

[19] G. Kickelbick, P. Wiede \& U. Schubert. "Variations in capping the $\mathrm{Zr6O} 4(\mathrm{OH}) 4$ cluster core: X-ray structure analyses of $[\mathrm{Zr} 6(\mathrm{OH}) 4 \mathrm{O} 4(\mathrm{OOC}-\mathrm{CH} \cdot \mathrm{CH} 2) 10] 2(\mu-\mathrm{OOC}-\mathrm{CH} \cdot \mathrm{CH} 2) 4$ and $\mathrm{Zr6}(\mathrm{OH}) 4 \mathrm{O} 4(\mathrm{OOCR}) 12(\mathrm{PrOH})$ $(\mathrm{R}=\mathrm{Ph}, \mathrm{CMe}=\mathrm{CH} 2), "$ Inorganica Chim. Acta 284, 1-7 (1999).

[20] S. Gross, G. Kickelbick, M. Puchberger \& U. Schubert. "Mono-, Di-, and Trimetallic Methacrylate-substituted Metal Oxide Clusters Derived from Hafnium Butoxide," Monatshefte für Chemie 1063, 1053-1063 (2003).

[21] S. B. Ötvös, O. Berkesi, T. Körtvelyesi \& I. Palinko. "Synthesis and Spectroscopic and Computational Characterization of $\mathrm{Zn} 4 \mathrm{O}$ ( Alicyclic or Aromatic Carboxylate ) 6 Complexes as Potential MOF Precursors," Inorg. Chem. 4620-4625 (2010).

[22] E. C. Mattson, S. M. Rupich, Y. Cabrera \& Y. J. Chabal. "Role of excess Ligand and effect of thermal treatment in hybrid inorganic-organic EUV resists," Proc. SPIE 10583, 1058309 (2018).

[23] R. Chen, Y. Li, L. Tang, H. Yang, Z. Lu, J. Wang, L. Liu \& K. Takahashi. "Synthesis of zinc-based acrylate copolymers and their marine antifouling application," RSC Adv. 7, 40020-40027 (2017). 